BHM (2016) Vol. 161 (Suppl 1): S1

DOI 10.1007/s00501-016-0466-6

(C) Springer-Verlag Wien 2016

\section{Foreword to Supplement}

\author{
Bruno Hribernik \\ Leoben, Austria
}

Published online March 15, 2016

It is with great pleasure and joy that, exactly 30 years after the international Liquid Metal Processing \& Casting Conference (LMPC)-or its predecessor-took place in Linz, this bi-annual conference returned to Austria and was welcomed with open arms:

More than 160 participants from 22 countries followed the invitation of the Austrian Metallurgical Society (ASMET) and gathered in Leoben to listen to presentations of papers from industry and science on topics including process modelling, innovative casting techniques, segregation, liquid treatment, and refining as well as on electroslag- and vacuum arc remelting.

Dr. Wolfgang Holzgruber, the founder of INTECO, former conference president of the 1985 LMPC and a participant in 2015, has summed up the enormous progress of electroslag remelting over the last three to four decades in an interesting review paper for this special issue of BHM.

Out of the numerous high quality conference papers, dealing with mathematical modelling and numerical simulation as well as experimental and industrial full-scale processing, the following papers have been selected:

The Development and Application of an intergrated VAR Process Model by S. Ballantyne

Effects of Low Frequency Alternating Currents on the Electro-Slag Remelting Process by R. Schneider, FH OÖ

Simulation and Testing of a Modified Mould, on Ugitech's ESRR $^{\mathrm{TM}}$ by C. Deville-Cavellin, Ugitech

The Influence of the Mould Cooling Temperature on the Surface Appearance and the Internal Quality of ESR Ingots by M. Kubin, INTECO

Production of Jumbo Blooms by Semi-Continuous Casting: Challenges, Feasibility and Future Potential by S. Michelic, INTECOTBR casting technologies $\mathrm{GmbH}$
My sincere thanks and congratulations to all authors, the conference co-chairmen Abdellah Kharicha and R. Mark Ward, the scientific committee, and Andreas Ludwig from the University of Leoben as well as to all paper reviewers for their excellent work.

Furthermore, I want to thank INTECO and Dr. Harald Holzgruber, who not only followed his father's footsteps and supported our efforts to bring LMPC back to Austria, but also was gold sponsor of the conference and made this special edition of BHM possible.

I very much hope that the selected papers will be of great interest to you. Enjoy!

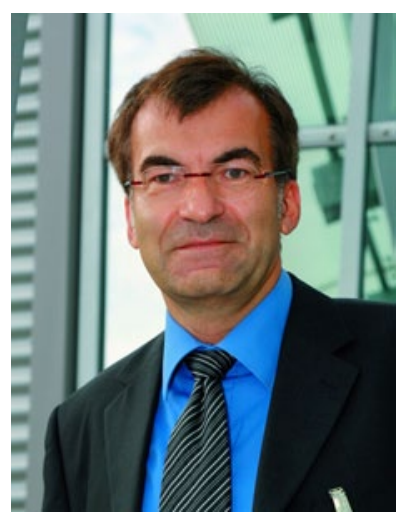

Bruno Hribernik

Executive Member of the Managing Board, ASMET 